\title{
Acute effects of starvation and treatment of rats with anti-insulin serum, glucagon and catecholamines on the state of phosphorylation of hepatic 3-hydroxy-3-methylglutaryl-CoA reductase in vivo
}

\author{
Richard A. EASOM* and Victor A. ZAMMIT $\dagger$ \\ Hannah Research Institute, Ayr, Scotland KA6 5HL, U.K.
}

\begin{abstract}
The fraction of 3-hydroxy-3-methylglutaryl-CoA (HMG-CoA) reductase in the dephosphorylated (active) form in rat liver in vivo was measured after various experimental treatments of animals. Intraperitoneal injection of glucose (to raise serum insulin concentrations) into rats $4 \mathrm{~h}$ into the light phase (L-4) resulted in a transient $(30 \mathrm{~min})$ increase in the expressed $(\mathrm{E}) /$ total $(\mathrm{T})$ activity ratio of HMG-CoA reductase without any change in total activity (obtained after complete dephosphorylation of the enzyme). Conversely, intravenous injection of guinea-pig anti-insulin serum into rats $4 \mathrm{~h}$ into the dark phase (D-4) significantly depressed the $\mathrm{E} / \mathrm{T}$ ratio within $20 \mathrm{~min}$. Intravenous injection of glucagon into normal rats at this time point did not affect the degree of phosphorylation of the enzyme, in spite of a 10-fold increase in hepatic cyclic AMP concentration induced by the hormone treatment. A 3-fold increase in the concentration of the cyclic nucleotide induced by adrenaline infusion was similarly ineffective in inducing any change in expressed or total activities of hepatic HMG-CoA reductase. However, when insulin secretion was inhibited, either by the induction of streptozotocin-diabetes or by simultaneous infusion of somatostatin, glucagon treatment was able to depress the expressed activity of HMG-CoA reductase (i.e. it increased the phosphorylation of the enzyme). Therefore insulin appears to have a dominant role in the regulation of the phosphorylation state of hepatic HMG-CoA reductase. In apparent corroboration of this suggestion, short-term $4 \mathrm{~h}$ food deprivation of animals before D-4 resulted in a marked decrease in the E/T activity ratio of reductase, which was not affected further by an additional $8 \mathrm{~h}$ starvation. By contrast, the total activity of the enzyme was not significantly affected by $4 \mathrm{~h}$ starvation, but was markedly diminished after 12 or $24 \mathrm{~h}$ starvation. Longer-term starvation also produced a chronic increase in the degree of phosphorylation of the enzyme. These results are discussed in relation to the role of reversible phosphorylation in the control of hepatic HMG-CoA reductase activity in vivo.
\end{abstract}

\section{INTRODUCTION}

A physiological role for changes in the phosphorylation state of hepatic HMG-CoA reductase (EC 1.1.1.34) in vivo has been established through the demonstration this parameter varies markedly in response to normal metabolic stimuli, such as those generated during the diurnal feeding cycle of the rat (Easom \& Zammit, $1984 b$ ). In addition, it has been shown that the fraction of HMG-CoA reductase in the active, dephosphorylated, state can be altered chronically in response to streptozotocin-induced insulin deficiency (Easom \& Zammit, 1985). The acquisition of such information on the changes in the phosphorylation state of the enzyme in vivo has been made possible through the development of the cold-clamping technique for sampling of rat liver (Easom \& Zammit, 1984a). The data obtained from these previous studies suggest that the diurnal variation in circulating insulin concentrations may be involved in the generation of the diurnal cycles observed for both total HMG-CoA reductase activity and the expressed/total
(E/T) activity ratio of the enzyme (Easom \& Zammit, 1985). However, it is not known how the effects of insulin may be integrated with those of other hormones. Because the concentrations of individual hormones reach peaks at different times with respect to the feeding cycle, an indication of their role should be provided by studies on the effects that food deprivation for shorter or longer duration has on the expressed and total activities of hepatic HMG-CoA reductase. Such studies should indicate the relative sensitivities of the two parameters to the withdrawal of the feeding stimulus at specific phases in the light/dark cycle, thus providing information about whether either parameter is more directly affected by a hormone released in response to feeding (e.g. insulin), or in anticipation of feeding.

The effects of insulin deficiency and supplementation that we described for hepatic HMG-CoA reductase in vivo (Easom \& Zammit, 1985) could be expected, at least qualitatively, from observations on the effects of insulin on the activity of HMG-CoA reductase in isolated rat liver cells (Ingebritsen et al., 1979). Similarly, the

Abbreviations used: HMG-CoA, 3-hydroxy-3-methylglutaryl-CoA; E/T ratio, expressed/total activity ratio.

* Present address: Department of Biochemistry, University of Texas Health Science Center, San Antonio, TX 78284, U.S.A.

$\dagger$ To whom correspondence should be addressed. 
opposing effects of glucagon and cyclic AMP on the E/T ratio of the enzyme in isolated liver cells (Ingebritsen et al., 1979; Henneberg \& Rodwell, 1985) were apparently confirmed by experiments in vivo in which infusion of the hormone into rats resulted in an increased incorporation of ${ }^{32} \mathrm{P}$ into the enzyme, with concomittant inactivation (Beg et al., 1980). However, in these latter studies the E/T activity ratios observed for saline-treated (control) animals were very low $(<15 \%)$ and outside the physiological range (Easom \& Zammit, 1984b, 1985). Consequently, a re-evaluation of the effects of glucagon on hepatic HMG-CoA reductase activity in vivo is required. Moreover, the interaction of the acute effects of insulin with those of counter-regulatory hormones (e.g. glucagon, catecholamines) on hepatic HMG-CoA reductase has not been studied in vivo. Experiments in which isolated liver cells are exposed to individual hormones (see above) do not yield information on the possible predominance of the effects of a particular hormone on individual hepatic functions in vivo (see, e.g., Cherrington \& Steiner, 1982; Johnston \& Alberti, 1982). This may be particularly relevant in the case of hepatic HMG-CoA reductase, because glucagon may induce increased phosphorylation not through direct stimulation of cyclic AMP-dependent protein kinase (Ingebritsen et al., 1978) but through increased phosphorylation of Inhibitor 1 (Ingebritsen \& Cohen, 1983). This protein, when phosphorylated, inhibits protein phosphatase 1, which may be involved in dephosphorylation of HMG-CoA reductase (Ingebritsen \& Cohen, 1983). Since insulin may exert its effects on the reductase by enhancing phosphatase activity (see Easom \& Zammit, 1985), both hormones may express their opposing effects on the phosphorylation state of reductase through modulation of its rate of dephosphorylation.

In the present study we have sought further to explore the identity of the stimuli that generate and maintain the diurnal cycles of total and expressed HMG-CoA reductase activity. In addition we have studied the changes in the phosphorylation state of the enzyme that occur in response to the acute modulation of the circulating concentrations of insulin, glucagon and catecholamines.

\section{MATERIALS AND METHODS}

\section{Animals}

The source and maintenance of the male Wistar rats used (140-160 g) were as described previously (Easom \& Zammit, 1984b). Their liver was sampled (see below) at the indicated times during the $12 \mathrm{~h}$-light $/ 12 \mathrm{~h}$-dark regimen under which they were maintained. Starved animals had their food withdrawn $4 \mathrm{~h}, 8 \mathrm{~h}$ or $24 \mathrm{~h}$ before liver sampling. Diabetes was induced by intraperitoneal injection of streptozotocin $(150 \mathrm{mg} / \mathrm{kg}$; see Easom \& Zammit, 1985). Rats with blood glucose concentrations $>30 \mathrm{~mm}$ were used 7 days later.

\section{Hormone and other infusions}

Bolus or continuous intravenous infusions were effected though an exposed femoral vein. Glucagon (1.25 mg/kg), adrenaline (0.6-1.5 $\mu \mathrm{g} / \mathrm{kg})$ and guinea-pig serum (either control or anti-insulin; see below) were administered by bolus injection of an appropriate volume $(0.2-1.0 \mathrm{ml})$ of saline or serum. Control animals received carrier only or control serum. Continuous infusions of catecholamines over $5 \mathrm{~min}$ (see above) or somatostatin (100-200 $\mu \mathrm{g} / \mathrm{kg}$ per h) were effected with a motorized syringe pump (Sage 341 ; A. R. Harwell, London, U.K.) and an indwelling catheter.

\section{Sampling of liver and preparation of microsomes (microsomal fractions)}

These procedures were performed as described previously (Easom \& Zammit, 1984a). Rats were anaesthetized (60 mg of pentobarbitone/ $\mathrm{kg}$ body wt.) $20 \mathrm{~min}$ before liver sampling; stress was lessened by handling of the animals for 5-7 days before the experiments (see Easom \& Zammit, 1984b). No systematic study of the effects of anaesthesia on reductase activity was undertaken. However, the period of anaesthesia was standardized (20 min) and animals that showed signs of respiratory stress or of insufficient insensibility at this time were discarded. Cold-clamped liver samples (approx. $1 \mathrm{~g}$ ) were homogenized in ice-cold medium containing $50 \mathrm{~mm}$ sucrose, $100 \mathrm{~mm}-\mathrm{KF}, 10 \mathrm{~mm}$-Tris/ $\mathrm{HCl}, 10 \mathrm{~mm}$-EDTA, 2 mM-dithiothreitol and $0.5 \mathrm{~mm}$-phenylmethanesulphonyl fluoride. The pH was 7.25 at $0^{\circ} \mathrm{C}$. Microsomes were prepared, essentially free of mitochondria, by differential centrifugation (Easom \& Zammit, 1984a).

\section{Assay of HMG-CoA reductase and other analyses}

Activity of HMG-CoA reductase was measured in the microsomes at $37^{\circ} \mathrm{C}$ as described previously (Easom \& Zammit, 1984b). 'Expressed' activity was assayed in microsomes prepared and washed in fluoride. 'Total' activity of HMG-CoA reductase was assayed in microsomes washed in chloride-containing medium and incubated with an exogenous rat liver protein phosphatase preparation (Brandt et al., 1975) for $10 \mathrm{~min}$ before assay (Easom \& Zammit, 1984b). Assay conditions were identical for both sets of microsomes.

The concentration of cyclic AMP in freeze-clamped liver samples was measured as described by Tovey et al. (1974). Blood glucose concentrations were determined as described by Bergmeyer et al. (1974). Protein concentrations were determined as described by Lowry et al. (1951).

\section{Materials}

The sources of these were as described previously (Easom \& Zammit, 1985). In addition, crystalline pig glucagon was a gift from Lilly Research Laboratories (Indianapolis, IN, U.S.A.) and streptozotocin was a gift from the Upjohn Co. (Kalamazoo, MI, U.S.A.). Cyclic somatostatin was obtained from Bachem U.K. (Saffron Walden, Essex, U.K.). $3^{\prime}, 5^{\prime}$-Cyclic $\left[8-^{3} \mathrm{H}\right]$ AMP for cyclic AMP assays was purchased from Amersham International (Amersham, Bucks., U.K.).

\section{RESULTS AND DISCUSSION}

\section{Effects of acute modulation of insulin concentrations}

In order to investigate the interaction of the effects of insulin with those of counter-regulatory hormones (glucagon, catecholamines), we sought to establish that the expressed (E)/total (T) activity ratio of hepatic HMG-CoA reductase was acutely responsive to alterations in the circulating concentrations of insulin in 


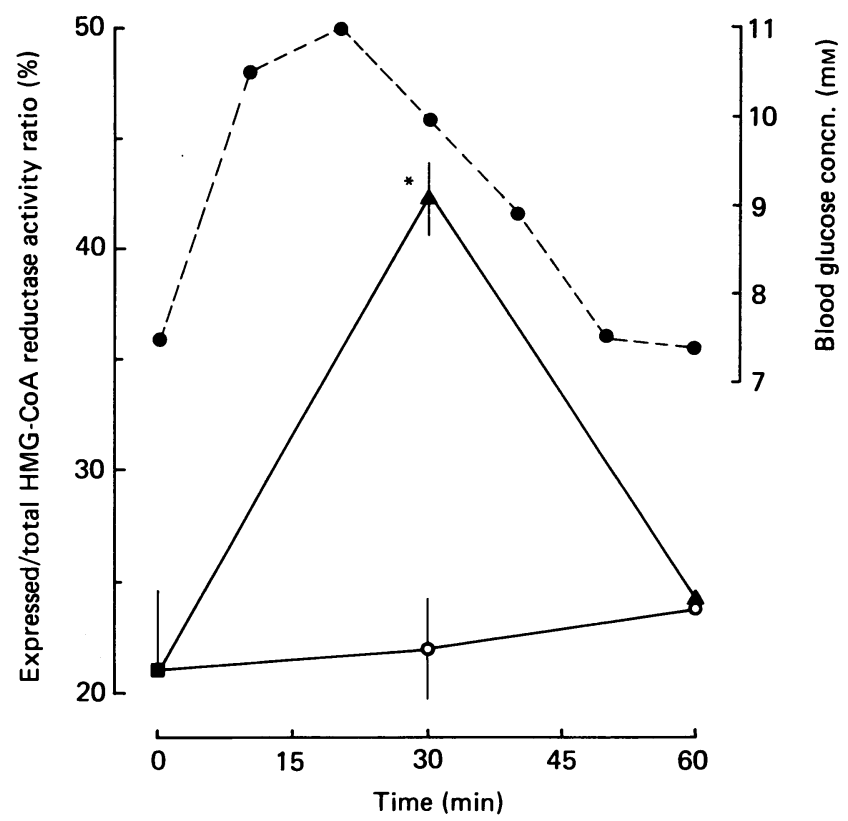

Fig. 1. Effect of intraperitoneal injection of glucose on the fraction of HMG-CoA reductase in the active state in rat liver microsomes

Anaesthetized rats (see the Materials and methods section) were injected with $0.8 \mathrm{ml}$ of saline alone $(O)$ or saline containing $200 \mathrm{mg}$ of glucose $(\Delta), 4 \mathrm{~h}$ into the light period (L-4). After the indicated time interval their abdominal cavity was opened and the left lateral lobe of the liver was cold-clamped. The activity of HMG-CoA reductase was measured in fluoride-washed microsomes (E) and in microsomes washed in chloride and incubated with exogenous protein phosphatase (T). The broken line describes the changes in blood glucose concentration of glucose-treated animals. No change in blood glucose occurred in control animals. Blood samples $(0.1 \mathrm{ml})$ were obtained from the cut ends of tail blood vessels. Values are means ( \pm S.E.M., where shown) of either three $(30 \mathrm{~min})$ or two $(60 \mathrm{~min})$ determinations; the asterisk denotes a statistically significant difference in $\mathrm{E} / \mathrm{T}$ ratio $(P<0.01)$ between the values for glucose-treated and control animals.

normal animals. Although we have previously demonstrated that insulin reversed the effects of experimentally induced diabetes (Easom \& Zammit, 1985), the doses of insulin used, as well as the state of the animals, in those experiments were non-physiological. In the present experiments we have induced relatively mild alterations of circulating insulin concentrations at times of the day that are characterized by low and high insulin concentrations $[4 \mathrm{~h}$ into the light period $(\mathrm{L}-4)$ and $4 \mathrm{~h}$ into the dark period (D-4) respectively (see Knox et al., 1977)]. Acute elevation of plasma insulin concentration in animals at L-4 was achieved by intraperitoneal injection of glucose (200 mg; Stansbie et al., 1976). This treatment resulted in a transient and modest increase in blood glucose concentration (Fig. 1); it was accompanied by a significant increase in the $\mathrm{E} / \mathrm{T}$ activity ratio for hepatic microsomal HMG-CoA reductase, which only lasted as long as the hyperglycaemia (Fig. 1). There was no change in $E / T$ ratio in saline-treated controls. A similar transient increase in blood glucose concentration was induced by intravenous infusion of guinea-pig antiinsulin serum into rats at D-4, as expected from a transient decrease in circulating insulin concentrations. The peak of this mild hyperglycaemia occurred 15-30 min after the bolus infusion and was accompanied by a significant decrease in the expressed activity of hepatic HMG-CoA reductase in the absence of any change in the total activity of the enzyme (Table 1). Control animals received normal serum and showed none of these changes.

\section{Effects of glucagon and somatostatin}

The infusion of glucagon into rats at the peak of the diurnal cycle of HMG-CoA reductase E/T-activity ratio (D-4) produced no changes in either expressed or total activity of the enzyme (Table 1). The liver was sampled $10 \mathrm{~min}$ after the bolus infusion. Effectiveness of glucagon action on the metabolism of the liver was ascertained (in addition to the marked tachycardia) by the accompanying hyperglycaemia (Table 1) and by the increase in hepatic cyclic AMP concentration induced by the hormone. The time course of the latter (Fig. 2) showed that the effect of glucagon on this parameter in vivo was very similar to that observed in vitro in isolated rat liver cells (Corbin et al., 1985). There was a greater than 10 -fold increase in hepatic cyclic AMP concentration during the first $6 \mathrm{~min}$ after infusion and a more gradual decline to normal values after about $15 \mathrm{~min}$. The observation that this action of glucagon on hepatic metabolism did not result in any concomitant change in the phosphorylation state of HMG-CoA reductase was surprising, in view of the effects of the hormone and of cyclic AMP on this parameter of the enzyme in isolated cells (Ingebritsen et al., 1979; Henneberg \& Rodwell, 1985). It suggested that increased cyclic AMP concentrations in hepatocytes in vivo are not obligatorily associated with increased phosphorylation of HMG-CoA reductase. It also suggested that, because glucagoninduced phosphorylation of HMG-CoA reductase can be observed in isolated cells but not in vivo, a counterregulatory factor present in vivo was overwhelming the effects of the marked increase in hepatic cyclic AMP (and possibly of cytosolic $\mathrm{Ca}^{2+}$; see Charest et al., 1983).

In order to test the possibility that the effects of glucagon were being antagonized by the increased secretion of insulin in response to the hyperglycaemia induced by glucagon infusion, we conducted the experiment under conditions in which insulin secretion was inhibited. We used streptozotocin-treated animals and rats that were infused simultaneously with somatostatin and glucagon. Under both these conditions, glucagon infusion resulted in a decreased expressed activity of HMG-CoA reductase in the absence of changes in total activity. Consequently the E/T activity ratio was significantly decreased (Table 1). Somatostatin infusion alone had no effect on either parameter. These observations suggested that, under normal conditions, the effects of insulin on hepatic HMG-CoA reductase phosphorylation state dominate over those of glucagon, even when the concentration of cyclic AMP is raised by the latter. In other experiments (results not shown) a 3-fold rise in hepatic cyclic AMP content induced by infusion of adrenaline into normal animals was also ineffective in altering the $E / T$ activity ratio for HMG-CoA reductase in normal animals. 
Table 1. Effects of glucagon and anti-insulin serum treatments of rats on the fraction of hepatic HMG-CoA reductase in the active form in vivo

Normal or diabetic animals were treated as indicated (see also the Materials and methods section) and their livers were sampled by cold-clamping after $10 \mathrm{~min}$ (glucagon) or $30 \mathrm{~min}$ (anti-insulin serum). When somatostatin was used, it was infused continuously for $10 \mathrm{~min}$ before and after the bolus injection of glucagon. Values are means ( \pm S.E.M.) for the numbers of determinations shown in parentheses. Those marked $(*)$ are significantly different $(P<0.02)$ from the values obtained for the corresponding control animals. 'Normal' denotes fed animals at D-4. Diabetic rats were also used at the D-4 time point.

\begin{tabular}{|c|c|c|c|c|c|}
\hline \multirow[b]{2}{*}{ Treatment } & \multirow{2}{*}{$\begin{array}{l}\text { State of } \\
\text { animal }\end{array}$} & \multirow{2}{*}{$\begin{array}{c}\text { Blood } \\
\text { glucose (mM) }\end{array}$} & \multicolumn{2}{|c|}{$\begin{array}{l}\text { HMG-CoA reductase activity } \\
(\mu \mathrm{mol} / \mathrm{min} \text { per } \mathrm{mg} \text { of protein) }\end{array}$} & \multirow[b]{2}{*}{$\mathrm{E} / \mathrm{T}$ ratio $(\%)$} \\
\hline & & & Expressed (E) & Total (T) & \\
\hline Saline control (5) & Normal & $7.3 \pm 0.1$ & $1.32 \pm 0.30$ & $1.86 \pm 0.33$ & $70.0 \pm 4.8$ \\
\hline Glucagon (4) & Normal & $11.4 \pm 1.0^{*}$ & $1.05 \pm 0.19$ & $1.44 \pm 0.22$ & $71.6 \pm 3.0$ \\
\hline Saline control (7) & Diabetic & $30.9 \pm 4.6$ & $0.37 \pm 0.07$ & $0.83 \pm 0.19$ & $49.6 \pm 5.0$ \\
\hline Glucagon (4) & Diabetic & $32.7 \pm 3.9$ & $0.27 \pm 0.10$ & $0.82 \pm 0.19$ & $30.3 \pm 6.6^{*}$ \\
\hline Somatostatin (4) & Normal & $8.4 \pm 1.0$ & $1.42 \pm 0.20$ & $2.06 \pm 0.33$ & $69.3 \pm 2.6$ \\
\hline Glucagon plus somatostatin (7) & Normal & $12.7 \pm 0.5^{*}$ & $0.88 \pm 0.14^{*}$ & $1.45 \pm 0.18$ & $59.8 \pm 3.5^{*}$ \\
\hline Control serum (9) & Normal & $8.5 \pm 0.3$ & $1.04 \pm 0.10$ & $1.62 \pm 0.11$ & $63.0 \pm 2.5$ \\
\hline Anti-insulin serum (6) & Normal & $10.8 \pm 1.3^{*}$ & $0.76 \pm 0.17^{*}$ & $1.57 \pm 0.18$ & $49.8 \pm 6.9^{*}$ \\
\hline
\end{tabular}

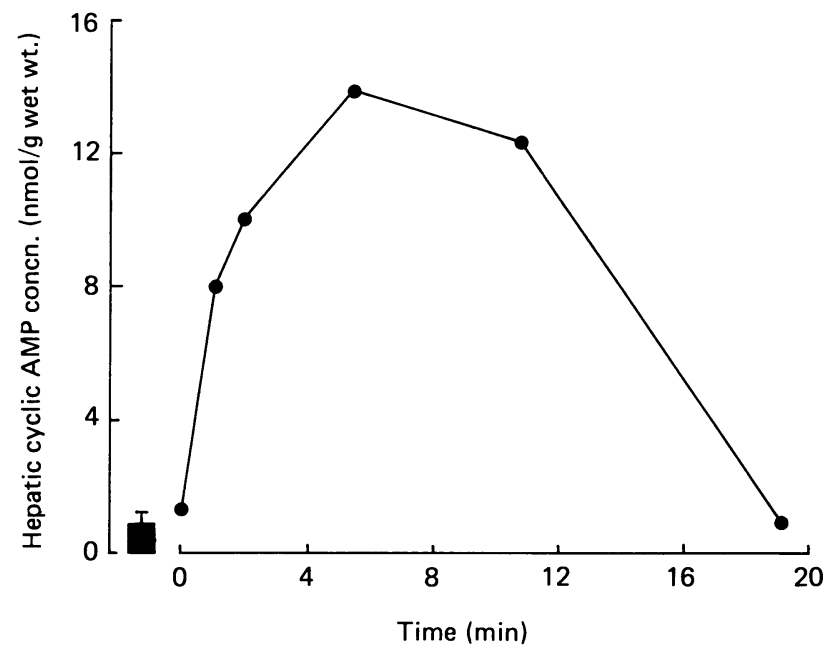

Fig. 2. Time course of the increase in hepatic cyclic AMP concentrations induced in vivo by intravenous injection of glucagon

Animals that were $3.5 \mathrm{~h}$ into the dark cycle were anaesthetized (see the Materials and methods section). After $20 \mathrm{~min}$ their abdominal cavity was opened and glucagon $(1.25 \mathrm{mg} / \mathrm{kg}$ body wt.) was injected (in $0.5 \mathrm{ml}$ of saline) into an exposed femoral vein. After the periods indicated, the left lateral lobe of the liver was freezeclamped. The time course was obtained by using different animals exposed to glucagon for different periods of time. The black symbol with bar indicates the control value ( \pm S.E.M.) found in normal rat liver (data taken from Steiner et al., 1972).

\section{Effects of food deprivation}

The physiological signals responsible for the generation and maintenance of the respective diurnal cycles of total activity and E/T activity ratio for hepatic HMG-CoA reductase are not known, although they are obviously related to the diurnal pattern of food intake of the rats (see Easom \& Zammit, 1984b). In an effort to determine the phases in the light/dark cycle at which such putative signals are generated, we withdrew food from animals for various periods of time $(4 \mathrm{~h}, 12 \mathrm{~h}$ and $24 \mathrm{~h}$ ) before sampling of the liver at D-4. The effects of these treatments on total and E/T activity ratios were studied. Long-term starvation $(24 \mathrm{~h})$ resulted in a marked $(80 \%)$ decrease in total enzyme activity as well as in the $\mathrm{E} / \mathrm{T}$ activity ratio (from $79.3 \pm 2.4 \%$ in control fed animals to $25.2 \pm 3.0 \%$ in starved animals). This observation confirms the inference from our previous studies on diabetic rats (Easom \& Zammit, 1985), namely that the phosphorylation state of HMG-CoA reductase can change chronically in response to altered physiological conditions. As a result of the combined effects of the changes in total activity of HMG-CoA reductase and of its phosphorylation state, the expressed activity was diminished to about $6 \%$ of control values after $24 \mathrm{~h}$ starvation.

Food withdrawal for $12 \mathrm{~h}$ had intermediate effects on both total activity and phosphorylation state. However, food withdrawal for $4 \mathrm{~h}$ had a much more marked effect on the E/T ratio than on total activity, such that, whereas the latter was only marginally decreased from control values, the expressed activity was decreased to less than half that in normal fed aniamls (Fig. $3 a$ ). Conversely, a further $8 \mathrm{~h}$ of food deprivation had an additional effect on total activity, but it had no effect on $\mathrm{E} / \mathrm{T}$ ratio in addition to that observed after only $4 \mathrm{~h}$ of food withdrawal (Fig. 3). These results suggested that the major determining signal for the high value of the $\mathrm{E} / \mathrm{T}$ activity ratio at D-4 in normal animals occurred between the L/D (light/dark transition) and D-4 time points. This is a period of most active feeding and is associated with peak circulating insulin concentrations (Knox et al., 1977). By contrast, the liver appeared to be committed to the attainment of the high total activity of the enzyme at D-4 by a signal that occurred before food withdrawal at $\mathrm{L} / \mathrm{D}$, such that the total activity of HMG-CoA reductase was still about 2 -fold higher at D-4 than at $\mathrm{L} / \mathrm{D}$, in spite of the lack of food intake during this 

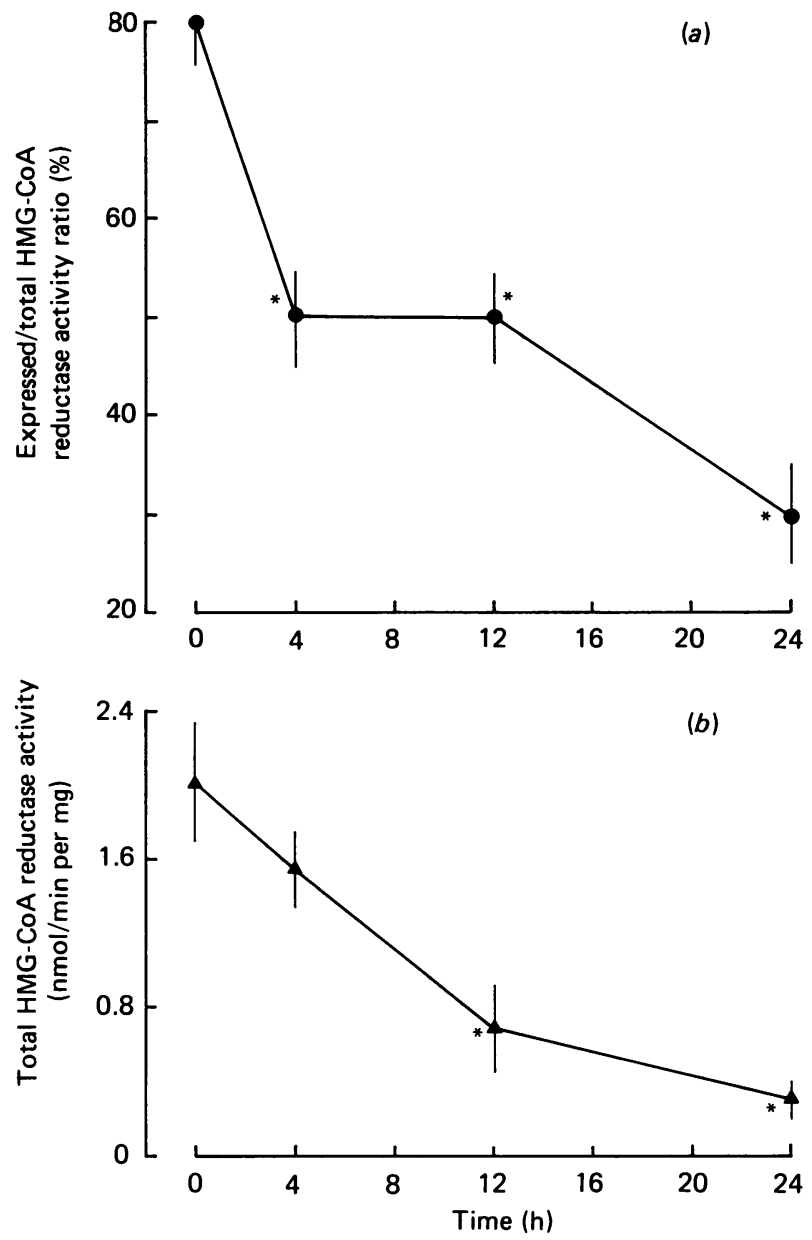

Fig. 3. Effects of withdrawal of food for different periods of time from rats on the expressed/total activity ratio (a) and total activity (b) of HMG-CoA reductase in liver microsomes at D-4

Food was removed from animals $4 \mathrm{~h}, 12 \mathrm{~h}$ or $24 \mathrm{~h}$ before sampling of the liver $4 \mathrm{~h}$ into the dark period (D-4). Expressed and total activities of HMG-CoA reductase activity were obtained as described in the legend to Fig. 1. Values are means ( \pm S.E.M.) for at least four separate determinations. Those that are significantly different from values for fed control rats $(P<0.05)$ are marked by an asterisk.

interval in $4 \mathrm{~h}$-starved rats. It is possible that the signal for the induction of synthesis of reductase $\mathrm{mRNA}$ is represented by the surge in corticosterone secretion that occurs at around L-10 (Knox et al., 1977) in anticipation of active feeding in normal animals.

\section{General discussion}

Some of the present observations illustrate the importance of testing the effects of hormones on hepatic metabolism in vivo whenever possible, in order to corroborate the effects produced on isolated liver cells (or perfused liver) in vitro. It is evident that, although glucagon can induce marked increases in phosphorylation of HMG-CoA reductase in isolated hepatocytes, its action is very effectively counteracted in the presence of normal circulating concentrations of insulin in vivo. Only when the latter are diminished (through induction of diabetes or short-term inhibition of insulin secretion by somatostatin) are elevated concentrations of cyclic AMP capable of resulting in increased phosphorylation of hepatic HMG-CoA reductase. Therefore it is suggested that insulin exerts a dominant effect in the regulation of HMG-CoA reductase activity by reversible phosphorylation in vivo. This may be similar to the role of insulin in glycogenolysis and in contrast with the dominant role of glucagon in the control of hepatic gluconeogenesis in vivo (Cherrington \& Steiner, 1982). Such a dominant role of insulin with respect to glucagon in the control of the phosphorylation state of hepatic HMG-CoA reductase in vivo may be analogous to the relationship between the effects of insulin and glucagon on adipose-tissue lipolysis in vivo: only under conditions of suppressed insulin secretion is lipolysis stimulated by glucagon (Gill et al., 1982). The mechanism(s) of action of insulin are still not well defined, and it is not possible, at present, to suggest how insulin overcomes the effects of increased hepatic cyclic AMP concentrations (but see Easom \& Zammit, 1985).

The requirement for stimulation of HMG-CoA reductase activity (and hepatic cholesterol synthesis) in synchrony with food intake (and concomitantly increased insulin secretion) would agree with a major role for insulin in the acute regulation of the activity of the enzyme, although it should be stressed that accompanying changes in bile acid secretion will also be important in determining $\mathrm{HMG}-\mathrm{CoA}$ reductase activity. In this respect, it is noteworthy that the major effect of short-term $(4 \mathrm{~h})$ food deprivation was a marked increase in the phosphorylation state of the enzyme. By contrast, the total activity of the HMG-CoA reductase appeared to be more sensitive to a signal that occurred before the light/dark transition and which was relatively insensitive to feeding during the first $4 \mathrm{~h}$ of the dark phase. Indeed, it is possible that the small decrease in total activity of HMG-CoA reductase observed after $4 \mathrm{~h}$ starvation was due not primarily to a decreased rate of synthesis of the enzyme but to an increased rate of degradation of the enzyme. Parker et al. $(1984,1985)$ and Marrero et al. (1986) have suggested that phosphorylation of the enzyme makes it a better substrate for proteinases and increases the rate of degradation of reductase in hepatocytes. Finally, the present data also highlight the fact that the phosphorylation state of HMG-CoA reductase not only changes transiently in response to acute hormonal changes but is also altered chronically by hormonal changes that accompany longer-term starvation, as previously observed in diabetes (Easom \& Zammit, 1985).

We thank Miss Anna Caldwell for expert assistance and $\mathrm{Mr}$. I. Mullaney for performing the cyclic AMP assays. R. A.E. was the recipient of a studentship funded by the Nutrition Consultative Panel of the United Kingdom Dairy Association.

\section{REFERENCES}

Beg, Z. H., Stonik, J. J. \& Bremer, H. B. (1980) J. Biol. Chem. 255, 8541-8545

Bergmeyer, H. U., Bernt, E., Schmidt, F. \& Starke, H. (1974) in Methods of Enzymatic Analysis (Bergmeyer, H. U., ed.), pp. 1196-1201, Academic Press, New York

Brandt, H., Capulong, Z L. \& Lee, E. Y. C. (1975) J. Biol. Chem. 250, 8038-8044 
Charest, R., Blackmore, P. F., Corkey, B. E. \& Williamson, J. R. (1983) J. Biol. Chem. 257, 8696-8704

Cherrington, A. D. \& Steiner, K. E. (1982) Clin. Endocrinol. Metab. 11, 307-328

Corbin, J. D., Beebe, S. J. \& Blackmore, P. F. (1985) J. Biol. Chem. 260, 8731-8735.

Easom, R. A. \& Zammit, V. A. (1984a) Biochem. J. 220, 733-738

Easom, R. A. \& Zammit, V. A. (1984b) Biochem. J. 220, 739-745

Easom, R. A. \& Zammit, V. A. (1985) Biochem. J. 230, 747-752

Gill, A., Johnston, D. G., Orskov, H., Batstone, G. F. \& Alberti, K. G. M. M. (1982) Metab. Clin. Exp. 31, 305311

Henneberg, R. \& Rodwell, V. W. (1985) Physiol. Chem. Phys. Med. NMR 17, 35-40

Ingebritsen, T. S. \& Cohen, P. (1983) Eur. J. Biochem. 132, 255-261

Ingebritsen, T. S., Lee, H.-S., Parker, R. A. \& Gibson, D. M. (1978) Biochem. Biophys. Res. Commun. 81, 1268-1277

Received 11 July 1986/26 August 1986; accepted 15 September 1986
Ingebritsen, T. S., Geelen, M. J. H., Parker, R. A., Evenson, K. J. \& Gibson, D. M. (1979) J. Biol. Chem. 254, 9986-9989

Johnston, D. G. \& Alberti, K. G. M. M. (1982) Clin. Endocrinol. Metab. 11, 329-361

Knox, A. M., Sturton, R. G., Cooling, J. \& Brindley, D. N. (1977) Biochem. J. 180, 441-443

Lowry, O. H., Rosebrough, N. J., Farr, A. L. \& Randall, R. J. (1951) J. Biol. Chem. 193, 265-275

Marrero, P. F., Haro, D. \& Hegardt, F. G. (1986) FEBS Lett. 197, 183-186

Parker, R. A., Miller, S. J. \& Gibson, D. M. (1984) Biochem. Biophys. Res. Commun. 125, 629-635

Parker, R. A., Miller, S. J. \& Gibson, D. M. (1985) Abstr. IUB Meet. 13th no. MO-347

Stansbie, D., Brownsey, R. W., Crettaz, M. \& Denton, R. M. (1976) Biochem. J. 160, 413-416

Steiner, A. L., Pagliara, A. S., Chase, L. R. \& Kipnis, D. M. (1972) J. Biol. Chem. 247, 1114-1120

Tovey, K. C., Oldham, K. G. \& Whelan, J.A. M. (1974) Clin. Chim. Acta 56, 221-234 